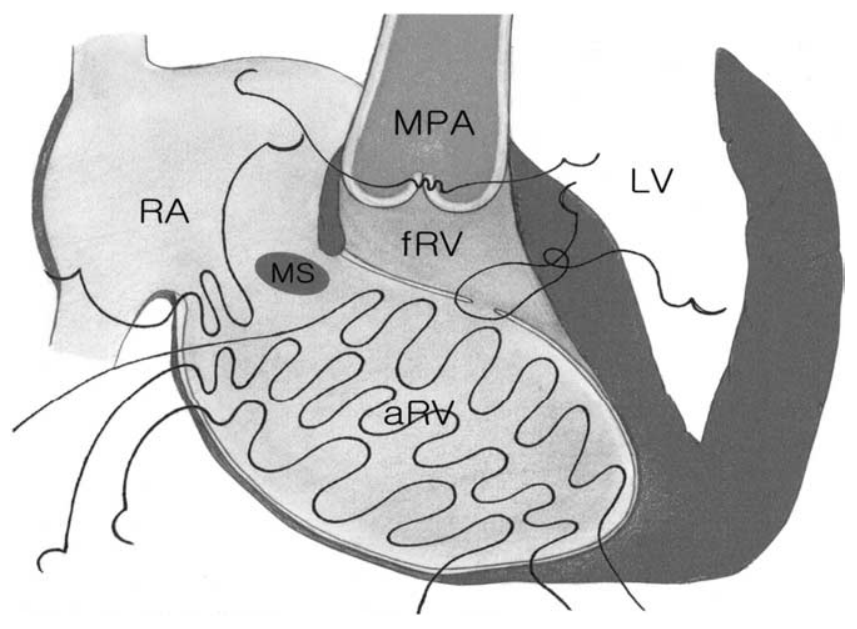

Figure 2. Schematic illustration showing the novel technique of atrialized right ventricle obliteration. RA, Right atrium; MS, Membranous septum; $a R V$, atrialized right ventricle; $f R V$, functional right ventricle; $M P A$, main pulmonary artery; $L V$, left ventricle. promote the appropriate growth of the once-hypoplastic lungs, which are compressed preoperatively by the severely enlarged right cardiac chambers in Ebstein's anomaly.

\section{References}

1. Starnes VA, Pitlick PT, Bernstein D, Griffin ML, Choy M, Shumway NE. Ebstein's anomaly appearing in the neonate: a new surgical approach. J Thorac Cardiovasc Surg. 1991;101:1082-7.

2. Van Son JA, Falk V, Black MD, Haas GS, Mohr FW. Conversion of complex neonatal Ebstein's anomaly into functional tricuspid or pulmonary atresia. Eur J Cardiothorac Surg. 1998;13:280-5.

3. Endo M, Ohmi M, Sato K, Tanaka T, Kakizawa H, Tabayashi K. Tricuspid valve closure for neonatal Ebstein's anomaly. Ann Thorac Surg. 1998;65:540-2.

4. Maeda M, Sai N, Miyahara K, Sakuri H, Nakayama M. Two staged Starnes operation for Ebstein's anomaly with pulmonary atresia in early infancy - a report of a success case. Jpn J Thorac Cardiovasc Surg. 1998;46:1200-5.

5. Adachi I, Ishzaka T, Ichikawa H, Kagisaki K, Kokai S. Midterm result of a case after Starnes operation. Jpn J Thorac Cardiovasc Surg. 2004;52:272-5.

\title{
Combined atrial arterial switch operation (double switch) for hearts with Shone syndrome and pulmonary hypertension
}
A. R. Hosseinpour, MD, FRCS (C-Th), M. Amanullah, FRCS (C-Th), I. R. Ramnarine, FRCS (Ed), 0. Stümper, MD, PhD,
D. J. Barron, MD, MRCP, FRCS (C-Th), and W. J. Brawn, FRCS, FRACS, Birmingham, United Kingdom

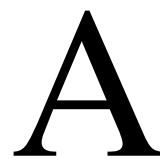

fter relief of obstructive lesions in Shone syndrome, left ventricular dysfunction might persist, with high left ventricular end-diastolic pressure (LVEDP) and pulmonary hypertension (PHT). ${ }^{1} \mathrm{We}$ reasoned that the right ventricle $(\mathrm{RV})$, having been trained by means of PHT, could support the systemic circulation. The left ventricle (LV), although dysfunctional in the systemic circulation, would be adequate to support the pulmonary circulation. With this arrangement, PHT might resolve. This was achieved

From the Department of Paediatric Cardiac Surgery, Diana, Princess of Wales Children's Hospital, Birmingham, United Kingdom.

Received for publication June 20, 2005; revisions received Sept 19, 2005; accepted for publication Sept 27, 2005.

Address for reprints: W. J. Brawn, FRCS, FRACS, Department of Paediatric Cardiac Surgery, Diana, Princess of Wales Children's Hospital, Steelhouse Lane, Birmingham, B4 6NH, UK (E-mail: william.brawn@ bch.nhs.uk).

J Thorac Cardiovasc Surg 2006;131:471-3

$0022-5223 / \$ 32.00$

Copyright $\odot 2006$ by The American Association for Thoracic Surgery doi:10.1016/j.jtcvs.2005.09.028 in 2 patients with the combined atrial and arterial switch procedure (double-switch procedure), which is usually used in congenitally corrected transposition. ${ }^{2}$

\section{Clinical Summary}

PATIENT 1. An 18-month-old boy $(7.5 \mathrm{~kg})$ with Shone syndrome and previous coarctation and parachute mitral valve repair presented with failure to thrive and PHT. His aortic valve was bicuspid. Preoperative evaluation showed severe mitral regurgitation and a non-apex-forming LV with endomyocardial fibroelastosis, although its end-diastolic diameter was normal (25 mm; predicted range, 21-31 mm). LVEDP was $17 \mathrm{~mm} \mathrm{Hg}$. Pulmonary artery (PA) pressures were $120 / 70 \mathrm{~mm} \mathrm{Hg}$ (mean, $85 \mathrm{~mm} \mathrm{Hg}$ ), decreasing to $65 / 50 \mathrm{~mm} \mathrm{Hg}$ (mean, $45 \mathrm{~mm} \mathrm{Hg}$ ) with increased inspired oxygen. Systemic pressures were 95/60 $\mathrm{mm} \mathrm{Hg}$.

A double-switch procedure was performed. A supravalve ring was excised from the mitral valve, and its anterior commissure was partially closed. A 13-mm pulmonary homograft was placed in the native aortic root (neopulmonary outflow tract) because coronary artery mobilization necessitated partial excision of the bicuspid aortic valve. Postoperative course was 


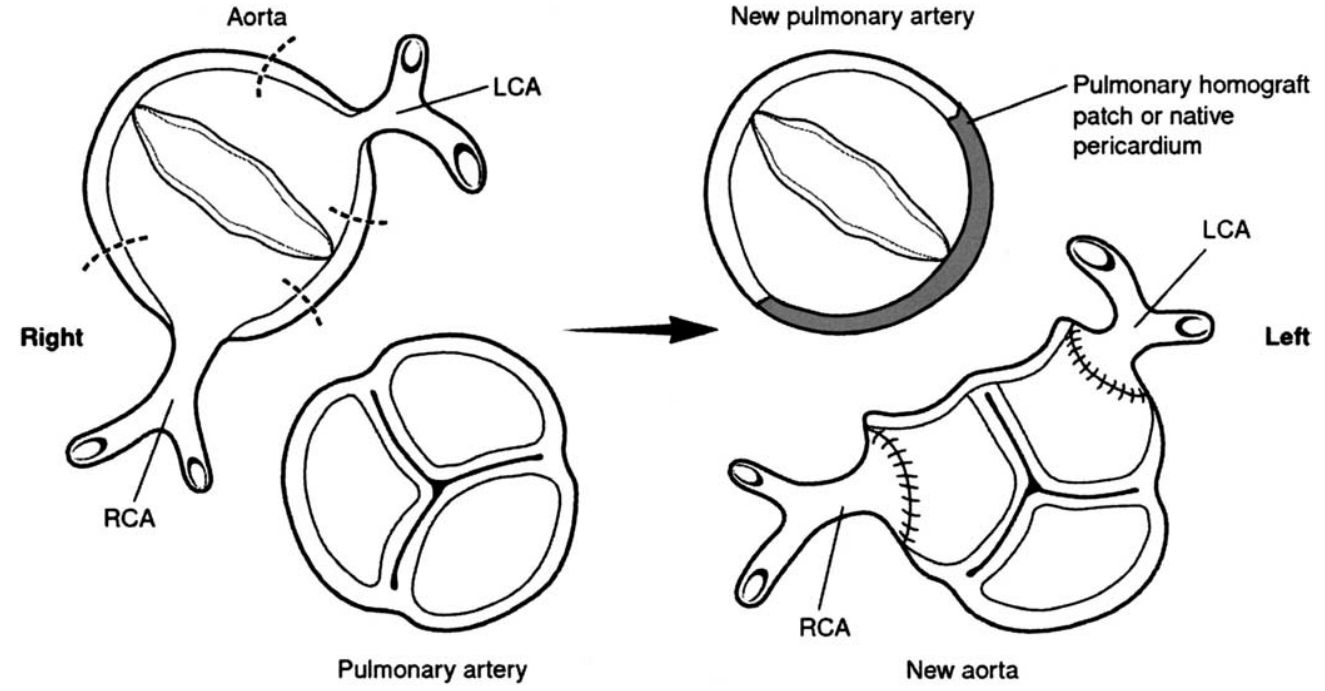

A

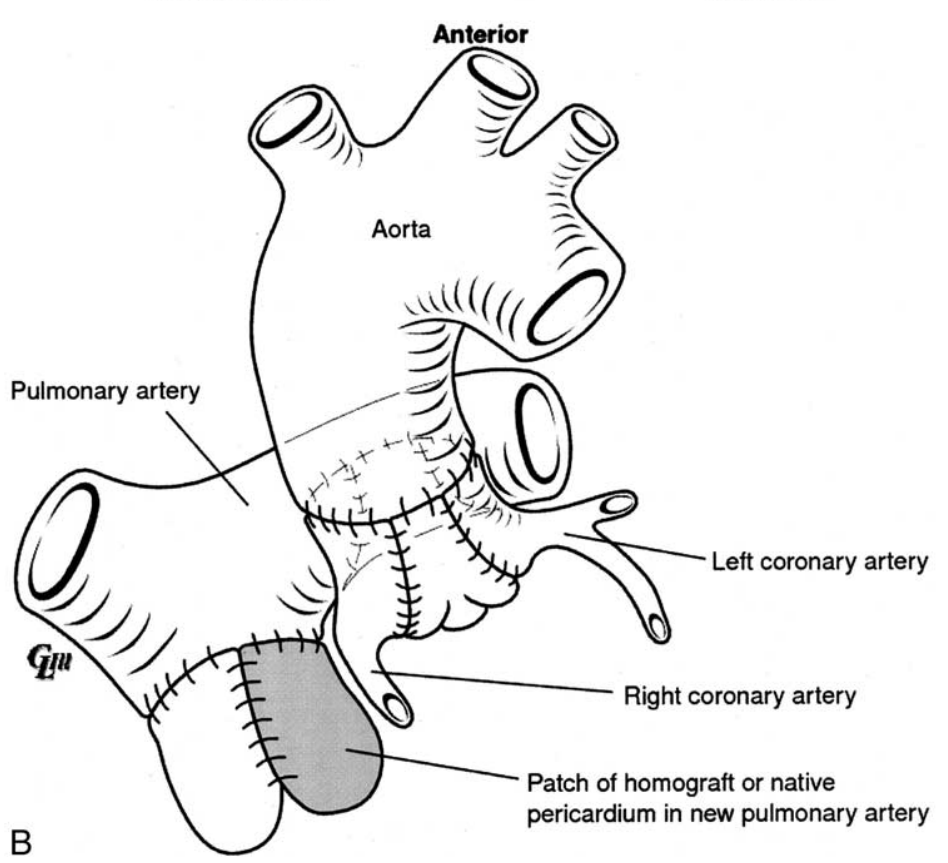

Figure 1. A, Diagram illustrating the relocation of the coronary arteries to medially hinged flaps in the new aorta. LCA, Left coronary artery; $R C A$, right coronary artery. B, Diagram illustrating the reconstructed new aorta and pulmonary artery, with the new aorta anterior to the pulmonary artery.

uneventful without pulmonary vasodilators (eg, nitric oxide), with extubation on the second day.

PATIENT 2. A 34-month-old girl $(10.9 \mathrm{~kg})$ with Shone syndrome and previous balloon valvuloplasty for aortic stenosis presented with failure to thrive and PHT. Preoperative evaluation showed severe tricuspid regurgitation, dysplastic mitral valve, a non-apex-forming LV with endomyocardial fibroelastosis, and an LVEDP of $28 \mathrm{~mm} \mathrm{Hg}$, although end-diastolic diameter was normal (32 $\mathrm{mm}$; predicted range, 23-35 $\mathrm{mm}$ ). PA pressures were 82/35 $\mathrm{mm} \mathrm{Hg}$ (mean, $52 \mathrm{~mm} \mathrm{Hg}$ ), with a wedge pressure of $24 \mathrm{~mm} \mathrm{Hg}$. Systemic pressures were $78 / 39 \mathrm{~mm} \mathrm{Hg}$. The reversibility of PHT was not tested because transpulmonary gradient was low.

A double-switch procedure was performed with tricuspid valve repair with De Vega annuloplasty. ${ }^{3}$ The mitral valve was not repaired. The postoperative course was complicated by high temperatures and an inflammatory response. The patient was extubated 8 days later. No pulmonary vasodilators were used. 


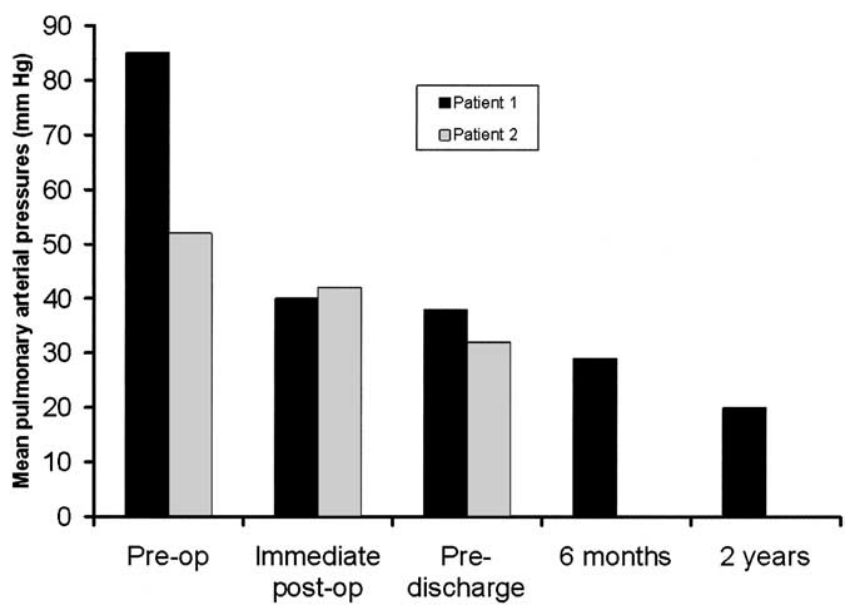

Figure 2. Graph illustrating the regression of mean pulmonary artery pressures after surgical intervention.

\section{Comments on Surgical Technique}

In healthy hearts the PA is anterior to the aorta. Accordingly, the newly neo-PA remained posterior to the reconstructed aorta (Figure 1). The coronary arteries required more mobilization than usual to relocate them to medially hinged flaps on the neoaorta. ${ }^{4}$ Routine cardiopulmonary bypass at $18^{\circ} \mathrm{C}$, periods of circulatory arrest, and crystalloid cardioplegia (repeated every 30 minutes) were used. Bypass, crossclamp, and total circulatory arrest times were 172, 150, and 56 minutes, respectively, in the first patient, and 174, 131, and 11 minutes, respectively, in the second. Postoperatively, adrenaline, dobutamine, and milrinone infusions were instituted.

\section{Results}

In both patients there was laminar flow in both outflow tracts and in the systemic and pulmonary venous pathways. PA pressures decreased immediately and continued to decrease over the follow-up periods (Figure 2). Right ventricular dysfunction persisted in the first patient who underwent heart transplantation 2 years later, when the mean PA pressure was $20 \mathrm{~mm} \mathrm{Hg}$. This was complicated by bleeding and cerebral injury. He died 3 months later. The second patient is progressing well and thriving 3 months after the operation. She has mild-to-moderate right ventricular dysfunction.

\section{Discussion}

Failure to thrive, PHT, and increased LVEDP might complicate relief of obstructive lesions in Shone syndrome. This was seen in our 2 patients and also reported in isolated aortic stenosis. ${ }^{5}$ Because of high LVEDP, small LV, and PHT, we believed that further surgical intervention to the left heart lesions, in particular the mitral valve, would not be successful. Cardiac transplantation was contraindicated because of PHT. Heart-lung transplantation was not considered because of its poor results.

We reasoned that if pulmonary venous pressures could be reduced, PHT should resolve. In both patients the RV was trained by using PHT at systemic pressures. We believed that the RV in the systemic circulation would be more efficient than the impaired LV and that its lower end-diastolic pressures would resolve the PHT. This was observed in the first patient, who later underwent transplantation for persisting right ventricular dysfunction. The second patient is markedly improved and thriving, with decreasing PA pressures.

The double-switch procedure is an extreme form of palliation for Shone syndrome but might allow resolution of PHT. The RV might support the systemic circulation for many years. If it fails, in the setting of low PA pressures, cardiac transplantation would be an option.

\section{References}

1. Brown JW, Ruzmetov M, Palaniswamy V, Hoyer MH, Girod D, Rodefeld MD, et al. Operative results and outcomes in children with Shone's anomaly. Ann Thorac Surg. 2005;79:1358-65.

2. Langley SM, Winlaw DS, Stumper O, Dhillon R, De Giovanni JV, Wright JG, et al. Midterm results after restoration of the morphologically left ventricle to the systemic circulation in patients with congenitally corrected transposition of the great arteries. J Thorac Cardiovasc Surg. 2003;125:500-7.

3. De Vega NG. Selective, adjustable and permanent annuloplasty. An original technique for the treatment of tricuspid insufficiency. Rev Esp Cardiol. 1972;25:555-6.

4. Brawn WJ, Mee RB. Early results for anatomic correction of transposition of the great arteries and for double-outlet right ventricle with subpulmonary ventricular septal defect. J Thorac Cardiovasc Surg. 1988;95:230-8.

5. Burch M, Kaufman L, Archer N, Sullivan I. Persistent pulmonary hypertension late after neonatal aortic valvotomy: a consequence of an expanded surgical cohort. Heart. 2004;90:918-20. 